\title{
The Fall and Rise of The Contingency Theory of Leadership
}

\author{
Ary Suharyanto \\ Magister Public Policy and Management, Faculty of Social and Political Sciences, Universitas Gadjah Mada \\ (email: arysuharyanto@mail.ugm.ac.id) \\ Rizky Dwi Lestari \\ Magister Public Policy and Management, Faculty of Social and Political Sciences, Universitas Gadjah Mada \\ (email: rizky.d.1@mail.ugm.ac.id)
}

\begin{abstract}
This article aims to look at the development of The Contingency Theory of Leadership which had developed in the 1970s, but declined in the 1990s, and has begun to be considered relevant again in handling major crises in recent years, including Covid-19. The study used a descriptive qualitative method to review the related literature. The Contingency Theory of Leadership with the main approach to leadership appropriate depending on the environmental situation that arises in the context of a particular action or behavior. Discovered in 1964 by Fiedler, then expanded in 1970, slowly declining until the 2010s. The number of catastrophes and major disasters in the world proves that the response of a leader to a crisis that is considered successful is one that can adapt to the context and circumstances. Some of the leader's characters that are relevant in crises are Achieving Situational Awareness, Adaptive Decision Making, Communication, Energy Management, and Learning. A crisis is a situation that requires high leadership sensitivity. It takes a certain character that can help with proper handling both before, during and after a crisis.
\end{abstract}

\section{Keywords:}

contingency; Covid-19; crisis; leadership

\section{Introduction}

Leadership is complex, there are many types of definitions and theories of leadership in various literatures (Yukl, 1989; Rost, 1991; Lussier and Achua, 2007; and Northouse, 2016). Leadership studies have a permissive and relativistic culture because the definition of an expert is as great as any other definition, so that somewhere in the range of 1900 and 1990 there were in excess of 200 unique meanings of authority (Rost, 1991). Apart from the many ways of conceptualizing, according to Northouse (2016) the concept of leadership basically consists of a process, involves influence, happens in bunches, and includes common objectives. During its development, leadership is studied in different ways so that it requires different definitions (Yukl, 1989; Lussier and Achua, 2007). The definition of leadership has 
also developed and changed along with the research trends that existed at that time (Yukl, 1989; Northouse, 2016). Several previous studies categorized various studies on leadership, as well as to see the development of leadership theory from time to time. Yukl (1989) tries to develop an understanding of leadership theory from the approach to traits, behavior, power, and situational factors in the 1980s time period. Lowe and Gardner (2000) developed a categorization of leadership theory based on the Trait, Behavioral, Contingency, MultipleLevel Approaches, Leadership and Information Processing, Neo-Charismatic Approaches, Other Prominent Approaches, New Directions in the 1990s. Gardner et al (2010) continued and developed Lowe and Gardner's (2000) research for the 2000-2009 period and added the Other approaches and New methods category. Meanwhile Dinh et al (2014) expanded the scope of use by Gardner et al (2010) and limited the time period from 2000 to 2012.

The Contingency Theory of Leadership is a leadership theory that was coined in 1964 and developed until the 1970s (Yukl, 1989). This theory was coined by Fiedler (1964) who was triggered by his anxiety over the existence of leadership effects in certain situations that could not be explained by previous leadership theories, which were mostly based on trait and behavioral paradigms (Vroom and Jago, 2007; Hernandez et al, 2011). As researchers develop interest in other leadership theories that also adapt to world developments that have begun to implement the NPM paradigm, interest in The Contingency Theory of Leadership has decreased (Yukl, 1989; Lowe and Gardner, 2000; Wart, 2013), this continued until the 2010s (Hernandez et al, 2011). Various disasters and major calamities in the world in recent years have invited several studies on the success of handling the crisis, the results of which have led to the relevance of The Contingency Theory of Leadership in certain situations (Hemmer and Elliff, 2019; Keen et al, 2020). So that the reason of this study is, to begin with, to see how the Contingency Theory of Leadership was created, developed, plummeted and re-developed. Second, to provide an overview of the relevance of The Contingency Theory of Leadership in crisis situations. Third, provide an overview of the character of The Contingency Theory of Leadership which is again relevant to crisis situations such as the Covid-19 pandemic. The three objectives will be answered with research questions: a) What is the background of the birth of The Contingency Theory of Leadership ?; b) How is the development of The Contingency Theory of Leadership ?; c) How is the relevance of The Contingency Theory of 
Leadership in a crisis situation ?; d) What are the characters of The Contingency Theory of Leadership that are relevant to handling situations during a crisis?

\section{The Contingency Theory of Leadership}

The Contingency Theory of Leadership was first put forward by Fred E. Fiedler (1964) in an article entitled A Contingency Model of Leadership Effectiveness. The basis of the approach to The Contingency Theory of Leadership is that the right type of leadership depends on the environmental situation that arises in the context of a particular action or behavior (Saha, 1979). According to Hernandez et al (2011), the emergence of the contingency theory approach in the 1960s and 1970s was an attempt to define the effects of leadership and explain more variations on the effectiveness of leaders that take into account situational factors more precisely. Leadership theory developed previously is usually based on a paradigm derived from traits, especially for the 1900s and behavioral for the 1930s (Vroom and Jago, 2007; Hernandez et al, 2011). Fiedler (1964) attempted to clarify that task-oriented leaders are more viable in exceedingly favorable or exceedingly unfavorable circumstances, whereas relationship-oriented leaders are more compelling in tolerably favorable circumstances, so that certain authority styles will be more successful depending on the circumstance in which they are set, not over time and circumstance.

In line with Fiedler (1964), House (1971) also proposed The Path Goal Theory which is included in the contingency theory group. This theory focuses on situational moderators on leader effectiveness. House (1971) developed this theory based on Vroom's (1964) theory of expectation motivation which in substance proposes that individuals are more likely to lock in in certain behaviors in the event that they see a tall probability that the behavior will lead to compensated results. Saha (1979) further explains the development of The Contingency Theory of Leadership, that Osborn (1975) in Saha (1979) broadens the applicable scope with the adaptive-reactive theory of leadership which sees "macro" variables that are rarely considered in a leadership approach. The "macro" variable consists of characteristics such as external environment, organizational size, technology, and various aspects of the organizational structure. Furthermore, Levine (1975) in Saha (1979) shows that leadership should not be conceptualized only as adaptive-reactive, but also proactive and entrepreneurial. The Contingency Theory of Leadership has proven to be one of the most valid 
and reliable measures of individual leadership potential (Waters, 2013). This variety of evidence, makes experts admit that the context of the situation affects the effectiveness of a leader.

\section{Methods}

This research uses descriptive qualitative method by examining various relevant literature. We base the assumption of decreasing or increasing development of leadership theory, in this particular case The Contingency Theory of Leadership, in the article of Yukl (1989); Lowe and Gardner (2000); Hernandez et al (2011); and Dinh et al (2014). The next discussion will be divided into three parts. First, we will describe the development of The Contingency Theory of Leadership from time to time to get an idea of how the interest of researchers rises and falls. Second, we will describe the meaning and relationship of leadership, crisis, and contingency in order to get an idea of the relevance of the three. Third, we will describe the results of a study on research related to leadership during the major crisis of the last few years to get an idea of what kind of leadership character is needed during the crisis, including the current Covid-19.

\section{Results and Discussion}

\section{The Journey of The Contingency Theory of Leadership}

The Contingency Theory of Leadership is a marriage between social psychology and management science that was popularly practiced in the late 1960s and 1970s (Rost, 1991). Fiedler (1964) built The Contingency Theory of Leadership with the hypothesis that leadership is generally considered an interpersonal circumstance in which one person in a gather has impact over another for the reason of performing a given assignment. Therefore, it is very important to know whether the group environment / situation will make it easier or more difficult for the leader to influence his group members. Fiedler (1964) contended that task-oriented leaders are more viable in exceedingly favorable or profoundly unfavorable circumstances, whereas relationship-oriented leaders are more compelling in tolerably favorable situations. This is supported by Fiedler and Chemers (1974) in Saha (1979), that The Contingency Theory of Leadership tries to coordinate people with suitable circumstances based on person authority styles. This means that in certain or abnormal circumstances (either 
above or below), effective leadership is one that is able to adapt or adapt to the situation at hand. An abnormal situation, more precisely above normal, was a crisis.

The development of leadership theory from time to time also causes a paradigm shift in researchers with the times. According to Yukl (1989), leadership theory with a basic situational concept (including The Contingency Theory of Leadership) is still developing, but it tends to move backward from extreme situationism to a more balanced theoretical perspective. Based on the identification of leadership theory over the last 100 years by Hernandez et al (2011), The Contingency Theory of Leadership developed in the 1960s to 1970s in an endeavor to more accurately characterize authority impacts and clarify more varieties in experimental thinks about of adequacy. leader. Lowe and Gardner (2000) examined the development of leadership theory research in the 1990-1999 period. According to Lowe and Gardner (2000), The Contingency Theory of Leadership is still in the rankings of the most publications in LQ, but it seems that the appeal of the contingency approach that was previously studied in leadership research in the 1960s and 1970s is fading, and with Trait Theories and Behavioral Theories have decreased in frequency of publication as the neocharismatic paradigm increases.

A study of the development of leadership theory for the period 2000-2009 conducted by Gardner et al (2010) concluded that research that focuses on traditional leadership theories, including The Contingency Theory of Leadership, has continued to decline in publication. Gardner et al (2010) revealed that the decline was one of the largest from $12 \%$ to only $1 \%$. This result is supported by Dinh et al (2014). The decline in publication interest in certain theories, according to Reichers and Schneider (1990) in Lowe and Gardner (2000) could be because these theories have reached a mature stage in construction development. According to Dinh et al (2014), the leadership theory group that was developing at that time included Ethical / Moral Leadership Theories, especially Servant leadership theory which, according to (Eva et al, 2019), increased significantly. This shift occurs in line with the increasing trend in the world of leadership which is expected to meet the demands of the New Public Management (NPM) and Good Governance paradigm where the leadership model is deemed appropriate.

The latest developments in leadership theory, especially with the many crises in the form of natural disasters, terrorism, and finally the Covid-19 pandemic, the world is again reminded of the need for effective leaders during a crisis, not just how to bring an organization 
more advanced and developing. Regarding the handling of the Covid-19 pandemic, for example, various studies have compared how state leaders deal with the pandemic in their region, for example those conducted by Keen et al (2020) and Dirani et al. (2020). Crisis situations are realized to be different from normal situations, so the handling and how a leader overcomes a crisis is also different. So that The Contingency Theory of Leadership becomes relevant again for discussion.

\section{Leadership, Contingency, and Crisis}

The definition of leadership can be complex and there is no single agreement (Rost, 1991; Waters, 2013; Northouse, 2016). During the period 1900 - 1990 there were more than 200 different definitions of leadership (Rost, 1991). Northouse (2016) defines leadership as a process where an individual influences a group of individuals to achieve common goals. The word "contingency" literally means a situation that is still shrouded in uncertainty and is beyond reach (KBBI, 2020). Fiedler (1964) revealed that The Contingency Leadership Theory tries to match individuals with appropriate situations based on the individual's leadership style. This means that in certain or abnormal circumstances (either above or below), effective leadership is one that is able to adapt or adapt to the situation at hand. An abnormal situation, more precisely above normal, was a crisis.

Smiar (1992: 149) in Hemmer and Elliff, 2019 defines a crisis as "when we, literally, not ourselves and the world around us really changes". Crises are characterized by low probability / high consequence events that threaten the most basic goals of an organization (Weick, 1988). In other literature there is a difference between crises and extreme conditions. Agreeing to Hannah et al (2009), an extraordinary may be a circumstance that undermines a sudden tall need objective with small or no reaction time, characterized by uncertainty of cause, impact, and implies of determination where the danger comes to the limit where the objective (for illustration, life or safety) not as it were has tall need but is additionally critical. Hannah et al (2009) also offer a model in assessing a condition that can be called extreme in five dimensions, namely Location in time / temporal ordering, Magnitude and probability of consequences, proximity, and attenuators and intensiers. Until now, the Covid-19 Pandemic has entered its 9th month if calculated since the first time WHO decided that Covid-19 had become a pandemic on March 11, 2020 (WHO, 2020) and had infected more than 50 million 
people and killed more than 1.2 million people worldwide (worldometer.info). Meanwhile, on the economic side, the IMF estimates that world economic growth will contract by $-4.4 \%$, an unprecedented condition (imf.org). So based on the model presented by Hannah et al (2009), the Covid-19 pandemic can be categorized as an extreme crisis condition.

Various studies on The Contingency Theory of Leadership have shown valid evidence of leadership effectiveness for certain individuals in certain situations (Taormina, 2008; Waters, 2013)). In any case, most critically for the consider of administration, The Contingency Theory of Leadership contends that leaders ought to not be anticipated to lead in each circumstance which organizations ought to attempt to put leaders in ideal circumstances (Finkelstein et al, 2008 in Waters, 2013). This is as experienced by various countries in dealing with the COVID-19 pandemic crisis, in a crisis situation, it can even be said to be extreme, until now it is still unknown when it will end, certain leadership styles are only suitable for situations in certain countries and cannot be generalized.

\section{Leadership in Crisis}

The need for leadership in times of crisis or even extreme is different from that of normal times. Moilanen (2015) says that leadership and choice making are diverse in a emergency from typical day-to-day operations. Leadership amid a disastrous occasion is around managing with scenes of danger and instability, feelings, and inescapable results that require prompt activity in a way that produces things return to ordinary (Boin and 't Hart, 2003; Rosenthal, Boin, and Comfort 2001 in Hemmer and Elliff, 2019). With the existence of unusual conditions, or in Fiedler's (1964) sense are highly unfavorable situations, or macro environmental factors as expressed by Osborn (1975) and Levine (1975) in Saha (1979), it can be concluded that unusual leadership is needed. or leadership that adapts to the situation. Next, we will outline leadership in crisis management in various worlds.

Hemmer and Elliff (2019) examined leadership in handling Typhoon Harvey Texas. The result of their evaluation is that the region's shifting vulnerabilities in emergencies such as storms put weight on leaders to arrange, think deliberately, and act fittingly when circumstances unfurl. They must take advantage of positive openings and oversee negative dangers and be done utilizing tactile, specialized and versatile work. Dirani et al (2020) examined leadership in relation to human resource management during the Covid-19 
pandemic. According to Dirani et al (2020), the government, communities and organizations are right now in emergency mode and are looking for direction from their leaders. It is time for genuine leader to assist frameworks and people overcome confinements and fears and progress their execution. The discoveries that can be underlined are that in times of emergency like this, administration must alter the conditions by promptly understanding the circumstance and reacting to it depending on intuitive and polished skill.

The Covid-19 pandemic has undoubtedly been one of the greatest crises in human history (Loayza and Pennings, 2020). Leadership in various countries has taught that in dealing with the COVID-19 pandemic crisis, certain leadership styles are only suitable for situations in certain countries. Various literature has also documented the response of governments around the world in dealing with pandemics with how politicians, related institutions and local governments make policies that actually destroy each other (Maor, 2020; Carter \& May, 2020; in Ciqi May, 2020) and the style of national government policies. which is adaptive to the situation that occurs serves to reconcile mutually destructive policy conflicts, especially how the leadership of the top leadership of the State can determine the appropriate national policy style in times of crisis.

China as the country of origin of the pandemic for three months was able to handle the pandemic well, it was recorded that at the end of March 2020, China had succeeded in controlling the spread of the pandemic with high-cost lockdown efforts in most of its main cities, especially Wuhan (Zhang et al, 2020) using the style leadership which in the view of some countries can be deemed to violate Human Rights (Kupferschmidt and Cohen, 2020). Policies that are even called "brutal but effective" (Guardian.com) China's success is a combination of the various steps taken by many policy actors, the top three chosen by 1000 respondents from an online survey of general population groups as the most important steps in The handling of Covid 19 in China is a strict lockdown, assistance for Hubei province, as well as the dismissal of the leaders of Wuhan City and Hubei Province, all three of which are traditional instruments in the authoritarian State system in responding to the crisis and in accordance with the state's authoritarian control of society (May, 2020) Although at the beginning of the handling of the pandemic, China still maintained a system mechanism known as "fragmented authoritarianism" (Lieberthal and Lampton (1992) in May 2020) where the relationship between the central government and local governments only acts as ex ante 
when policy objectives are made and ex post when assessments dila policy kukan, meaning that the highest authority for handling the pandemic rests with the local government, but on January 25 there was a turning point in the change in leadership style shown by Xi Jinping by taking over directly openly and stating that 'I myself ordered and directed' (qinzi zhihui, qinzi bushu) handling of covid-19, the fact is that the change in how to lead Xin Jinping directly resulted in the role of the regional governments of Hubei and Wuhan being only pure implementers (May, 2020) And since then Wuhan has implemented several extreme policy steps. From the initial chaos that occurred in the handling of Covid 19 to the shift in policy logic to a centralized leadership style was an important turning point in China's victory against the pandemic (Hood \& Lodge, 2006 in May, 2020) and this also changed the logic of local governments from formulating, supervisory. and policy implementers become pure executors who with all efforts must fulfill the objectives of central policies. So it can be said that the accuracy of changing the leadership of the most important person in China is China's greatest achievement in dealing with the spread of the pandemic.

The combination of policies that China has successfully pursued is not necessarily a series of best efforts that can simply be transferred to other countries. Rather, it is a policy combination befitting of China's authoritarian system featuring centralized leadership, bureaucratic mobilization, and lessons learned by Cihna about successful policy combinations in the previous crisis (May, 2020). Changes in leadership style to be centralized according to the situation of the State of China. Similar to China, Vietnam, although not as "brutal" as China in dealing with the pandemic, has also implemented various strict policies that have worked well thanks to its authoritarian system of government (weforum.org).

When China as the primary nation to involvement the widespread took such extraordinary steps to halt the spread, the nation has been emphatically criticized by the Western world. But at that point fair many months afterward when the infection started to spread quickly and claimed numerous casualties in western nations, leaders within the Joined together States and Europe started to alter their sees and arrangements (Binagwaho, 2020) including the leadership style used by China in dealing with the pandemic crisis.

America is starting to see how China is doing very well in dealing with the pandemic and the US federal government is starting to try to change their policy viewpoint by considering the lockdown strategy and indeed, when the initial phase of the pandemic 
spreads the decision to lockdown was the policy of the central government. Because the best way to prevent the spread is to limit the mobilization of people and keep them away from each other because there was no best treatment at that time and a vaccine was not yet available, and lockdowns are the optimal strategy in dealing with COVID-19 in the early stages of the spread of the pandemic (Zhang et al. 2020).

That as it may, this step isn't something that's simple to actualize, be that as it may since the starting President Donald Trump deliberately maintained a strategic distance from appearing a clear part for the government government, the US government government tended to be fractional in plans for a national lockdown or a territorial lockdown (Atlantic.com, 2020) when President Trump attempted to alter his authority fashion by straightforwardly managing with this widespread, checked by his ask to isolate the states of Unused York, Unused Shirt and parts of Connecticut as an exertion to halt the spread of the Covid 19 Infection, indeed some time recently the alter happened when this thought was criticized by Unused York Senator Andrew Cuomo with said that the Government Government does not have any specialist to uphold lockdowns, lockdowns are something that China is doing and usually America (CNBC.com, 2020) it is illegal action and could be prosecuted. This debate is the impact of the federal system of government adopted by the United States, which is rooted in the "very ambiguous division of powers" at the heart of American-style federalism, as argued (Kettl, 2020) and therefore the power of the federal government in implementing direct policy. in the form of a limited lockdown, this causes the federal government to become a weak guide and indeed a national strategy that was designed to deal with a clear pandemic never existed, this is what makes the handling of the pandemic in America directed individually by their respective states without an election basis strong policies, finally the strategy in dealing with covid is returned to the ability of state leaders. President Trump "leaves the job to the governor, and the nation stumbles under the consequences" (Washington post in Kettl, 2020) the consequences that follow a successful experiment by one state can be shared with other states and experiments that are not optimal are discarded. . America shows a situation of great friction between the federal and state governments that no other country has had before (Kettl, 2020), especially in the handling of the Covid 19 pandemic. The description above explains that the authoritarian leadership style in America is completely unacceptable in the country's situation. Until today, the United 
States has recorded its failure to handle the pandemic and accounts for nearly 40 percent of the total COVID-19 cases in the world along with Brazil (Global Times.com, 2020). Until the present time, America has not discovered an initiative style that is generally fitting to America's circumstance in managing the pandemic.

Whereas South Korea recorded another interesting phenomenon in handling the pandemic, South Korea did not take extreme steps at all in efforts to deal with a pandemic such as lockdowns by closing major cities or imposing severe travel restrictions, but both reported low levels of pandemic spread (Zhang et al ,2020). The victory of South Korea is frequently misjudged that the deciding figure for its victory is since South Korea carries out dictator ways in which South Korean citizens are portrayed as having tall compliance and surrendering to government control due to the leftovers of dictator run the show in 1970s and 1980s (Park et al, 2020).

In any case, on the opposite, South Korea taken care of the widespread with a totally non-authoritarian authority fashion and instep coordinated its technique towards gigantic tests in collaboration with private parties in Korea. The South Korean government is leveraging cooperation with the private sector in the Public Private Partnership scheme to increase the number of Real-Time Polymerase Chain Reaction (RT-PCR) tests exponentially. With this PPP scheme, the South Korean government develop on Emergency Use Activation (EUA) of Real-Time Polymerase Chain Reaction (RT-PCR) test-kits carried out and developed by innovators from the In Vitro Diagnostics (IVD) industry of South Korea under the Law The Infectious Disease Control and Prevention Act (IDPCA) (Park et al, 2020).

There is something interesting in handling the pandemic, especially the leadership carried out by Moon Jae In as the leader of South Korea, who is under threat of impeachment which has been discussed as the best option if proven to fail in dealing with the pandemic, but immediately President Moon Jae In was able to alter open conclusion radically to succeed in winning the common decision once more in April 2020. This turning point is caused by the leaders of the South Korean state with its law based government realizing and being mindful of their destiny within the following race, so that they are forced to work well in emergency administration, and in this way they turn to procedure which is speedier, to be specific mobilizing open and private implies to win against the widespread (Park et al, 2020) This situation that threatens the stability of this government is exploited by the South Korean 
leader to pressure his government to work optimally by choosing the most likely strategy. can be used in the country's situation, so that South Korea can achieve success with its unique strategy of fighting the Covid 19 pandemic.

The above phenomena reinforce the relevance of The Contingency Theory of Leadership in handling various crises, that the most appropriate leadership must be adapted to the situation that occurs, certain leadership styles will only be successful in certain country situations, and whenever applied to different nations whose circumstances are obviously extraordinary, at that point the likelihood of disappointment will be incredible. The literature from The Contingency Theory of Leadership has been able to show the impact of this situation and enable researchers to predict the possible effectiveness of certain leadership in certain situations (Taormina, 2008 in Richard D Waters, 2013). In any case, the foremost critical thing for The Contingency Theory of Leadership in leadership studies is that you just ought to not anticipate leaders to be able to lead in each circumstance and it is accurately the assignment of the organization that must attempt to put the leaders in an ideal circumstance (Finkelstein, 2008 in Waters, 2013) so that his leadership achieve optimal success too. Be that as it may nations that have fizzled in their administration due to their disappointment to evaluate the circumstance, political disappointment or disappointment to moderate the widespread as a danger have dispensed genuine misfortunes on their nations and the world, clearing out numerous individuals to endure which this enduring can really be anticipated by great authority (Binagwaho, 2020). A crisis situation is indeed a big challenge for leadership studies to determine what kind of leadership can survive the crisis and after the crisis.

Based on research on several crisis and extreme events in the world, Keen et al (2020), Hemmer and Elliff (2019), and Goralnick et al. (2015) suggested things that must be done in leadership, namely: first, Achieving Situational Awareness. Leaders must characterize their current circumstance and reality, both inside the organization and remotely. Utilizing what they know as truths, and what they accept to be genuine (suspicions), leaders must rapidly create a need activity arrange. Leaders must regularly verbalize a vision and a arrange of activity (procedure, objectives, strategies, and needs). Hemmer and Elliff (2019) add that leaders must plan, think strategically, and act appropriately when situations unfold. Second, Adaptive Decision Making. Amid a emergency, indeed the foremost working organizations and groups discover out that their ordinary forms and hones for doing commerce cannot meet 
the requests of current circumstances and modern substances. To succeed, they must adjust some time recently making basic choices rapidly. In Haiti, after an seismic tremor, it is basic to move rapidly to spare the lives of those buried beneath the rubble of the seismic tremor or reach those who have suffered life-threatening wounds. Now and then, meaning we do not have all the data we need, so we have to be work with deficient information or data. Hemmer and Elliff (2019) include that authority in this delayed emergency is completely illustrated through tangible creation and specialized and versatile work.

Third, Communication. Leaders ought to endeavor to communicate in a way that addresses what the group of onlookers must listen - not fair what the leader needs to say. Such an approach requires a profound understanding of desires of the target group of onlookers and the hones that back this reason. Communicate essentially and clearly the "things to do" of the circumstance inside a clear time outline - maintain a strategic distance from "great things to do" and "great things to do". Clarify needs and rehash them frequently. Concurring to Hemmer and Elliff (2019) leaders must work together and take advantage of their position to decrease approach breakdown. Goralnick et al (2015) also stated that in crisis management an effective communication strategy and information system were essential. Fourth, Energy Management. As the COVID reaction creates, weariness will result. To avoid burnout and oversee vitality for the long term, we advocate the center guideline simply must pay attention of yourself so that you simply can see after your group. We suggest that you just "make a fight beat," which permits you to function at a maintainable pace over time, Fifth, Learning. As well frequently leaders who are submerged in emergency may come up short to keep in mind every day authority lessons. To maintain a strategic distance from this trap, open wellbeing experts have the one of a kind opportunity to act as "member eyewitnesses" by capturing and sharing the many lessons learned from the COVID 19 widespread reaction. Another leadership imperative is for leaders to instill learning forms and best hones to expect or diminish probability. and end of the impacts of enduring. By doing so, leaders are able to supply quick strategic reactions to emergencies whereas building long-term key capabilities. Hemmer and Elliff (2019) include that leaders draw from schedule past encounters to assist direct them through crises; However, they too ought to adjust and enhance, moreover regularly utilizing offbeat approaches to tackling issues. 


\section{Conclusion}

Leadership is complex, there are numerous sorts of definitions and speculations of authority in different literary works (Yukl, 1989; Rost, 1991; Lussier and Achua, 2007; and Northouse, 2016). Fiedler (1964) built The Contingency Theory of Leadership which tries to coordinate people with suitable circumstances based on their administration fashion. This theory could be a marriage between social brain research and management science that was prevalently practiced within the late 1960s and 1970s (Rost, 1991). Concurring to Hernandez et al (2011), the development of The Contingency Theory of Leadership within the 1960s and 1970s was an endeavor to characterize the effects of leadership and clarify more varieties on the viability of leaders that take under consideration situational components more absolutely. Leadership theory created already is ordinarily based on a worldview inferred from characteristics particularly for the 1900s and behavioral for the 1930s (Vroom and Jago, 2007; Hernandez et al, 2011).

The theory of leadership continues to develop from time to time, the paradigm of researchers has also shifted over time. Results of the study According to Yukl (1989), Lowe and Gardner (2000), Gardner et al (2010), Hernandez et al (2011), and Dinh et al (2014) The Contingency Theory of Leadership since it was first coined in 1964 had experienced significant development until the 1970s, then began to decline in the 1980s to 2010s. One of the reasons is the development of the NPM paradigm which is followed by various leadership criteria that are considered to support it (Wart, 2013). The latest developments with many crises in the form of natural disasters, terrorism, and finally the Covid-19 Pandemic, the world is reminded of the need for effective leaders during a crisis.

Crisis is defined as "when we are, literally, not ourselves and the world around us actually changes" (Smiar, 1992: 149 in Hemmer and Elliff, 2019). If contingency is defined as a situation that is still shrouded in uncertainty and is beyond reach (KBBI), then crisis is included in that definition. Even further, Hannah et al (2009) provide a view of the bigger crisis or what is called an extreme crisis. Various crises in the form of natural disasters, terrorism, and the Covid-19 Pandemic which is said to be one of the greatest crises of all time require unusual leadership, which is able to adapt to the conditions and situations at hand. Hemmer and Elliff (2019), and Goralnick et al. (2015) suggest what must be done in leadership in crisis situations, first, Achieving Situational Awareness, Leader must characterize their 
current circumstance and reality, both inside and outside the organization. Second, Adaptive Decision Making, amid a crisis, indeed the foremost working organizations and groups know that their ordinary forms and hones for doing trade cannot meet the requests of current circumstances and unused substances. Third, Communication, the Leader must endeavor to communicate in a way that addresses what the gathering of people has to listen - not fair what the leader needs to say. Fourth, Energy Management, leaders must take care of themselves and the team by creating a crisis management rhythm. Fifth, Learning, earn from past encounters and listen the conclusions of specialists in their areas.

\section{References}

Ayman, R., Chemers, M. M., \& Fiedler, F. (1995). The contingency model of leadership effectiveness: Its levels of analysis. The Leadership Quarterly, 6(2), 147-167. https://doi.org/10.1016/1048-9843(95)90032-2

Binagwaho, A. (2020). We need compassionate leadership management based on evidence to defeat COVID-19. International Journal of Health Policy and Management, 9(10), 413414. https://doi.org/10.34172/ijhpm.2020.73

Dinh, J. E., Lord, R. G., Gardner, W. L., Meuser, J. D., Liden, R. C., \& Hu, J. (2014). Leadership theory and research in the new millennium: Current theoretical trends and changing perspectives. Leadership Quarterly, 25(1), 36-62. https://doi.org/10.1016/j.leaqua.2013.11.005

Dirani, K. M., Abadi, M., Alizadeh, A., Barhate, B., Garza, R. C., Gunasekara, N., Ibrahim, G., \& Majzun, Z. (2020). Leadership competencies and the essential role of human resource development in times of crisis: a response to Covid-19 pandemic. Human Resource Development International, 23(4), 1-15. https://doi.org/10.1080/13678868.2020.1780078

Eva, N., Robin, M., Sendjaya, S., van Dierendonck, D., \& Liden, R. C. (2019). Servant Leadership: A systematic review and call for future research. Leadership Quarterly, 30(1), 111-132. https://doi.org/10.1016/j.leaqua.2018.07.004

Fiedler, F. E. (1978). The Contingency Model and the Dynamics of the Leadership Process. Advances in Experimental Social Psychology, 11(C), 59-112. https://doi.org/10.1016/S0065-2601(08)60005-2 
Fiedler, F. E. (1964). A Contingency Model of Leadership Effectiveness. Advances in Experimental Social Psychology, 1(C), 149-190. https://doi.org/10.1016/S00652601(08)60051-9

Gardner, W. L., Lowe, K. B., Moss, T. W., Mahoney, K. T., \& Cogliser, C. C. (2010). Scholarly leadership of the study of leadership: A review of The Leadership Quarterly's second decade, 2000-2009. Leadership Quarterly, 21(6), 922-958. https://doi.org/10.1016/j.leaqua.2010.10.003

Goralnick, E., Halpern, P., Loo, S., Gates, J., Biddinger, P., Fisher, J., Velmahos, G., Chung, S., Mooney, D., Brown, C., Barnewolt, B., Burke, P., Gupta, A., Ulrich, A., Hojman, H., McNulty, E., Dorn, B., Marcus, L., \& Peleg, K. (2015). Leadership during the Boston Marathon Bombings: A Qualitative After-Action Review. Disaster Medicine and Public Health Preparedness, 9(5), 489-495. https://doi.org/10.1017/dmp.2015.42

Gostin, Lawrence et al ( 2020, Maret 31) Why There's No National Lockdown, Enforcing a large-scale quarantine would be legally murky, even if it's what the country needs to slow the spread of the coronavirus. Theatlantic.dom Retrieved from https://www.theatlantic.com/ideas/archive/2020/03/why-theres-no-national lockdown/609127/

GT, staff reporters (2020) US, Brazil most 'failed' COVID-19 states. globaltimes.com Retrieved from https://www.globaltimes.cn/content/1192770.shtml

Hannah, S. T., Uhl-Bien, M., Avolio, B. J., \& Cavarretta, F. L. (2009). A framework for examining leadership in extreme contexts. Leadership Quarterly, 20(6), 897-919. https://doi.org/10.1016/j.leaqua.2009.09.006

Hemmer, L., \& Elliff, D. S. (2020). Leaders in action: The experiences of seven Texas superintendents before, during, and after Hurricane Harvey. Educational Management Administration and Leadership, 48(6), 964-985. https://doi.org/10.1177/1741143219873073

Hernandez, M., Eberly, M. B., Avolio, B. J., \& Johnson, M. D. (2011). The loci and mechanisms of leadership: Exploring a more comprehensive view of leadership theory. Leadership Quarterly, 22(6), 1165-1185. https://doi.org/10.1016/j.leaqua.2011.09.009

House, R. J. (1971). Administrasi science quarterly. Administrative Science Quarterly, 16(3), 321-339. http://www.jstor.org/stable/2391905?seq=1\#page_scan_tab_contents 
imf.org (2020) https://www.imf.org/en/Topics/imf-and-covid19/Policy-Responses-toCOVID-19

Keen, P. K., Gilkey, R., \& Baker, E. L. (2020). Crisis leadership - From the Haiti earthquake to the COVID pandemic. Journal of Public Health Management and Practice, 26(5), 503505. https://doi.org/10.1097/PHH.0000000000001207

Kettl, D. F. (2020). States Divided: The Implications of American Federalism for COVID-19. Public Administration Review, 80(4), 595-602. https://doi.org/10.1111/puar.13243

Kimball, Spencer (2020) New York Gov. Cuomo says Trump has no authority to impose quarantine: 'It would be illegal'. CNBC.com Retrieved from https://www.cnbc.com/2020/03/28/ny-gov-cuomo-says-trump-has-no-authority-toimpose-quarantine.html

KBBI (2020) https://kbbi.web.id/kontingensi

weforum.org..2020.https://www.weforum.org/agenda/2020/03/vietnam-contain-covid-19limited-resources/

Lowe, K. B., \& Gardner, W. L. (2000). Ten years of The leadership quarterly. The Leadership Quarterly, 11(4), 459-514. https://doi.org/10.1016/s1048-9843(00)00059-x

McMullin, C., \& Raggo, P. (2020). Leadership and Governance in Times of Crisis: A Balancing Act for Nonprofit Boards. Nonprofit and Voluntary Sector Quarterly, 1-9. https://doi.org/10.1177/0899764020964582

Mei, C. (2020). Policy style, consistency and the effectiveness of the policy mix in China's fight against COVID-19. Policy and Society, 39(3), 309-325. https://doi.org/10.1080/14494035.2020.1787627

Moilanen, J. H. (2015). The Wisdom of Tacit Knowing-in-Action and Mission Command. Adult Learning, 26(3), 101-108. https://doi.org/10.1177/1045159515583258

Morhman, A. M. J., \& Lawler, E. E. I. (1984). A Review of Theory and Research. In The Information Systems Research Challenge: Proceedings of the Harvard Business School Colloquium (pp. 135-164).

Newman, J. M., \& Krzystofiak, F. . (1993). from the SAGE Social Science Collections . Rights Reserved . The ANNALS of the American Academy of Political and Social Science, 503(1), 122-136. 
Park, J., \& Chung, E. (2021). Learning from past pandemic governance: Early response and Public-Private Partnerships in testing of COVID-19 in South Korea. World Development, 137(April 2020), 105198. https://doi.org/10.1016/j.worlddev.2020.105198

Rost, J. (1991). Leadership an the twenty first centiry. In Journal of Chemical Information and Modeling (Vol. 53).

Schein, E. H. (2010). Organizational Culture and Leadership (4th ed.). Jossey-Bass A Wiley Imprint.

Styles, M., Leadership, T., Traits, P., Styles, L., Models, L., Making, D., Culture, O., \& Team, M. (2010). AAGP Annual Meeting 2010. In The American Journal of Geriatric Psychiatry (Vol. 18, Issue 3). https://doi.org/10.1097/01.jgp.0000369161.13792.ad

Kupferschmidt and Cohen. (2020). Can China's COVID-19 strategy work elsewhere?. Science Vol 367, Issue 648206 March 2020

Van Wart, M. (2013). Administrative leadership theory: A reassessment after 10 years. Public Administration, 91(3), 521-543. https://doi.org/10.1111/padm.12017

Vroom, V. H., \& Jaago, A. G. (2007). The role of the situation in leadership. American Psychologist, 62(1), 17-24. https://doi.org/10.1037/0003-066X.62.1.17

Waters, R. D. (2013). The role of stewardship in leadership: Applying the contingency theory of leadership to relationship cultivation practices of public relations practitioners. Journal of Communication Management, 17(4), 324-340. https://doi.org/10.1108/JCOM-05-2012-0041

Weick, E. (1988). Enacted Sensemaking in Crisis Situations. July.

WHO (2020) ww.who.int/director-general/speeches/detail/who-director-general-s -openingremarks-at-th e-mission-briefing-on-covid-19---12-march-2020

Zhang, X., Ji, Z., Zheng, Y., Ye, X., \& Li, D. (2020). Evaluating the effect of city lock-down on controlling COVID-19 propagation through deep learning and network science models. Cities, 107(June), 102869. https://doi.org/10.1016/j.cities.2020.102869 